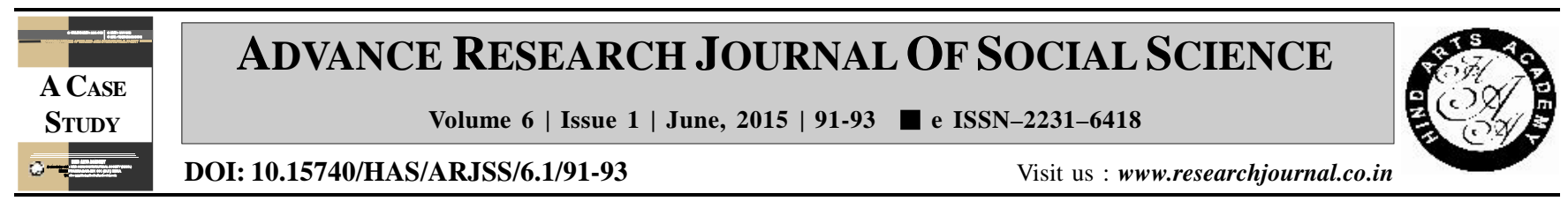

\title{
Constraints faced by user in the use of ICT tools like "KMS"
}

Sonam Agrawal* and N.K. Khare

Jawaharlal Nehru Krishi Vishwavidyalaya, JABALPUR (M.P.) INDIA

\section{ARTICLE INFO :}

$\begin{array}{lll}\text { Received } & : & 26.08 .2014 \\ \text { Accepted } & : & 24.05 .2015\end{array}$

KEY WORDS :

Kisan Mobile Sandesh, Constraint, Suggestion

HOW TO CITE THIS ARTICLE :

Agrawal, Sonam and Khare, N.K. (2015).

Constraints faced by user in the use of

ICT tools like "KMS". Adv. Res. J. Soc.

Sci., 6 (1) : 91-93.

*Author for correspondence

\begin{abstract}
This study was conducted during 2012-13 in the Jabalpur district of M.P. to find out constraint use in KMS and their suggestion. A total of 117 respondents were selected randomly for the study. Results showed that, Majority of KMS beneficiaries face the problems related to network of cell phone $(72.6 \%)$ followed by problem related to content of message $(59.8 \%)$, non-availability of KMS related literature $(50.4 \%)$, problem related to language $(40.1 \%)$, lack of information and technical guidance from extension functionaries $(31.6 \%)$, untimely delivery of message $(28.2 \%)$ and lack of extension activities $(21.3 \%)$. Suggestion found that the number of messages per week should be 5 and in Hindi language and the number of words should be 185 . This research paper shows the constraint and their suggestions in flow of information exchange and enhance knowledge achievement in Agricultural information dissemination.
\end{abstract}

